\title{
Information Technology and Its Impact on Employment of Knowledge Management Processes: A Case Study: Ministry of Education in Jordan
}

\author{
Senan Amer \\ University of Miskolc \\ Faculty of Economic in Miskolc \\ Hungary \\ E-mail: sinanboss10@gmail.com \\ István Kunos \\ University of Miskolc, \\ Faculty of Economic in Miskolc \\ Hungary \\ E-mail: szvkunos@uni-miskolc.hu
}

\begin{abstract}
This study aimed to identify the application of Information technology and its impact on Employment of Knowledge management in Ministry of education in Jordan, to achieve the objectives of this study, the researchers designed a questionnaire includes (46) questions; in order to collect the primary data from the study sample which consists of (80) employees at Ministry of education in Jordan. Researchers have examined whether information technology increases the practices of Employment of Knowledge management in the organizations. The literature to date appears to demonstrate that there is a strong relationship between the information technology and employment of knowledge management in boosting organizations. This conclusion suggests that the effectiveness of knowledge employment and information technology must be improved, and future studies should further investigate their role in enhancing information technology in organizations.
\end{abstract}

Keywords: Information technology; Employment of Knowledge Management; Ministry of Education in Jordan.

\section{Introduction}

The 21 st century has brought new and important challenges in society, due to the highly competitive business environment, which has risen from a rapid succession of changes all around the world. In other words, various phenomena of globalization have impacted international competition and made clear that a strong economy is, in fact, a knowledge-based economy. The exchange of knowledge in various fields has unquestionably increased and has become an integral part of the development of any product or service, which must be protected and preserved. This has resulted in the emergence of many relevant international agreements, accompanied by the remarkable activity of the World Intellectual Property Organization worldwide (Portes, 1997).

Knowledge is seen as a fundamental feature that distinguishes human societies from one another, and it can be argued that gaining this important wealth and resource is a critically valuable asset in the vast knowledge economy. This knowledge is considered the umbrella of development within the technological revolution, and is an important economic advantage for a society in all aspects of life. Knowledge plays a prominent role in making profound transformations in the performance of individuals, countries, and institutions, with the goal of gaining economic competitive advantage by adding great value to economic products through increasing productivities and demands for technologies and new ideas. Therefore, it is necessary to intensify the efforts of individuals, as well as our collective societies, and direct attention to all elements of knowledge in order to aid the development of means and tools, which will serve different aspects of life and facilitate advancements in development and society (Bontis, 2001).

\section{The study importance:}

The importance of research runs parallel to the importance of information technology and employment of knowledge management Processes, both playing strong roles of paramount importance in achieving many of the benefits and regulatory influences. Therefore, the present research attempts to explain and clarify the nature of information technology and its role in founding modern employment of knowledge management Processes in all its forms and tools in addition to the need to highlight the role played by the application of Information technology in the four Employment of Knowledge management processes. 
Employment of Knowledge management is a process of paramount importance in achieving many of the benefits and regulatory influences, so it was necessary to study the relationship between them and the application of Information technology, as this study is a supplement of the scientific efforts to highlight the concept of Employment of Knowledge management and Information technology, to show the benefits that can be derived from the applying. This study's results would be useful in identifying the mechanisms of future work which facilitate the work of Employment of Knowledge management and to be linked with the benefits that could be derived and the obstacles faced by the effectiveness of their application in the field of Information technology.

\section{Objectives of the Study:}

The main objective of this study is to investigate the relationship between information technology and employment of knowledge management process. The literature to date appears to demonstrate that there is a strong relationship between information technology and the employment of knowledge. In addition, the study aims to provide a comprehensive theoretical framework of the concepts of Employment of Knowledge Management and Information technology. In addition, identify the extent of the application of Employment of Knowledge management and Information technology at the Ministry of education in Jordan. In addition, identify the role of the application of Information technology in the Employment of Knowledge management processes. Moreover, provide a set of suggestions and recommendations to enhance the role played by the application of Information technology in Employment of Knowledge management at the Ministry of education in Jordan.

\section{The problem of Study:}

The literature review outcomes demonstrated inconsistent results, although the studies mostly displayed a significant relationship overall. This conclusion suggests that the effectiveness of knowledge, employment, and IT must be improved and that future studies should further investigate their role in enhancing the employment of knowledge management processes to aid policymakers and researchers to evaluate this role in such practices. Therefore, this study aims to review relevant literature which investigates the relationship between the employment of knowledge management and IT. Thus, the problem can be formulated as an overall question: What is the impact of the application of Information technology on Employment of Knowledge management processes in Ministry of Education in Jordan? And therefore the study's hypotheses have been developed.

\section{Hypotheses of the Study:}

The main hypothesis of the study was built depending on the study problem and its various elements which Represented in:

Ho1: No statistically significant impact at $(\mathrm{P}<0.05)$ for the application of information technology on the four processes of employment knowledge management (acquisition and creation of knowledge, save and store knowledge, share, and transfer of knowledge and apply and use of knowledge) in the Ministry of educations in Jordan. Derived the following sub-hypotheses:

- Ho1.1: No statistically significant impact at a level $(\mathrm{P}<0.05)$ for Physical Ingredients on the Processes of employment knowledge management in the Ministry of educations in Jordan.

- Ho2.1: No statistically significant impact at a level $(\mathrm{P}<0.05)$ for software (communication, database) on the Processes of employment knowledge management in the Ministry of educations in Jordan.

- Ho3.1: No statistically significant impact at a level $(\mathrm{P}<0.05)$ for human resources on the processes of employment knowledge management in the Ministry of educations in Jordan.

\section{Model of the study:}

Independent variable

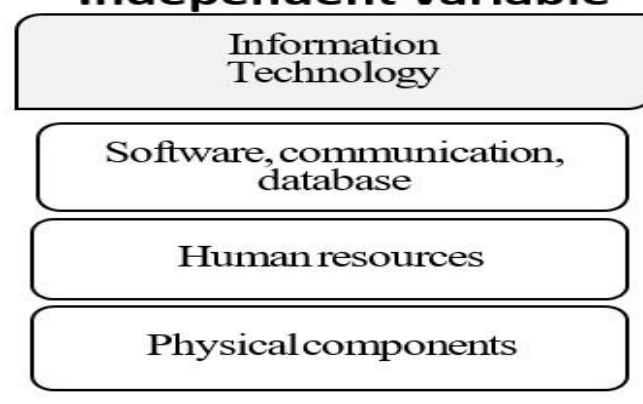

\section{Dependent variable}

Employment of knowledge management process

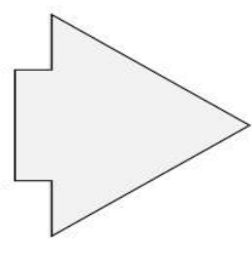

Figure 1 Model of the study 


\section{Theoretical Framework}

\subsection{Knowledge Management}

\subsubsection{The concept of knowledge management:}

The concept of knowledge management refers to the investment of data, information, facts, and ideas associated with one another, whereas data is the raw material, which must be regulated and arranged to develop the skills, abilities, and experiences of individuals (Vosko, 2006). Nonaka and Konno (1998) define knowledge as a specific human process in which perceptions, personal concepts, ideas, facts, information, and data all interact to produce knowledge. In this study, however, the researcher found that knowledge is a product of mental processes, which achieve concepts and ideas, values, personal and public beliefs, and are used in recognizing facts and events, and managing them as required and necessary.

Zagzebski (2017) defineKnowledge management as The ability of an individual to understand and develop an individual perception of the actualities around him or her, and the awareness of such acquisitions, as well as the acquisition of information through testing, observation, and reflection. Knowledge and awareness may be achieved by observing others, and their actions. In addition, one's findings are seen and reflected upon by others, and the amount of knowledge management is linked quickly to the intuition and diligent search, the discovery of unknown things, and the development of individual capabilities depending on conclusions reached. Pike\& Marr (2005)defines Knowledge management as a set of avenue and processes that are clear and specific, designed to detect and define activity in different types of processes, management, identify products or new strategies, enhance the management of human resources, and achieve several other goals."Employment of Knowledge management processes" term was associated with the processes or stages in order to gain, dissemination, storage, application, and using the knowledge for useful purposes. It consists of the following major processes (Inkpen\& Dinur ,1998):

a) The acquisition of knowledge: means the discovery of new knowledge through various internal sources such as stores of knowledge, through the sharing of experiences, conferences, seminars, or through financial and Economic data ... etc.

b) Store of knowledge: save and use by the knowledge management systems such as expert systems, so that Knowledge is stored in the organizational memory, which contains the existing knowledge in different ways.

c) Dissemination of knowledge: knowledge sharing and increase the capabilities of knowledge workers, their Skills and competencies through regular training programs, to focus on organizational learning.

d) Application of knowledge: means to make it more suitable for use in the implementation of the Organization's activities, more related to the tasks, benefit from this knowledge after filing and storing, and develop the ways of retrieval and transfer to the workers.

\subsubsection{The Importance of Employing Knowledge management}

The importance of knowledge lies in creating an organizational environment that encourages individuals to participate effectively in raising and improving the level of knowledge of all individuals, and to gather intelligent ideas that contribute to the diffusion of positive behaviors, while correcting ideas and investment behaviors, as well as social misconceptions (Leonard\& Sensiper, 1998). More specifically, the importance of employing knowledge lies in the following points:

- Determining the methods needed to find, reach and serve customers, and meet their needs through IT tools.

- Determining how institutions obtain their place in the competitive market share.

- Rearranging employees' ideas and accumulated knowledge of investments.

- Gaining customers' satisfaction and loyalty.

- Achieving innovation and development of modern technological tools and technologies to contribute to investment management and facilitate investment tasks.

- Reduce the time required by workers to obtain new knowledge.

- Provide a comprehensive and clear understanding of new initiatives and technologies.

\subsubsection{Characteristics of Knowledge Management Recruitment}

The process of employing knowledge is characterized by those who have concern for knowledge-bases and their sources within the institution, and they seek to develop the organizational cultures of the institutions through a common conceptual system between what is true and not true in the investor's community and the investment's laws and objectives in the institution itself (Chen\& Huang, 2009).

The system for the employment of knowledge in the investment field is considered a simple system, which allows managers and employees to obtain the required knowledge and information in a timely and efficient manner. It is also seen as an organizational linguistic system that is easy to understand, implement and regulate. 
Besides, it allows individuals to access the required information and provides possible mobility through modern tools and technologies (Wilson, 2002).

\subsubsection{Steps to Develop Knowledge management}

To take advantage of knowledge produced and acquired, it is necessary to analyze the knowledge itself in order to realize and understand the policies, in which knowledge is applied, and to identify appropriate types of knowledge and anticipate solutions and problems, as well as defining the goal of employing knowledge. Besides, this further simplifies knowledge production and development; as well as storing, organizing and categorizing this knowledge to make it easier to find when needed (Robinson, et al 2006). There are also steps, which may be taken to employ knowledge in investments, as reported in Denning's (2006) study as follows:

- Identifying the overall objective and sub-goals of knowledge use.

- Selecting knowledge recruitment strategies and tools.

- Distribute tasks among those responsible for recruiting and managing knowledge.

- Knowledge organization and its components of data, information, facts, and ideas.

- Raising awareness and spreading of the culture associated with this knowledge.

- Determine the scope and spread of knowledge and its beneficiaries.

- Examine of knowledge used prior to employment.

- Assessment of knowledge occurs after recruitment, and an examination of the knowledge and innovations generated by the recruitment.

\subsubsection{Forms of Knowledge management}

There are many research views and opinions, which speak to the forms and classifications of knowledge. Buckland (1991) perceives knowledge as being represented in data, facts and letters, and the information as multiform with varieties that have been processed to be meaningful. The forms of knowledge are illustrated in:

- Shared: Knowledge transferred between individuals and investment institutions.

- Synthetic: Characterized by clarity.

- External: A transfer of knowledge from a person to a book or message.

- Internal: Information transitioning from clear to implicit.

According to such, the researcher reveals that it is difficult to limit knowledge to a specific pattern or classification due to its branches in different fields. It can found in the form of data, information, facts, digital ideas, and quality, and sometimes we find it takes the form of synthetic, common, internal and external knowledge. In other research knowledge, classification appears in quality and quantity, and it should be noted that these differences enrich knowledge and development.

\subsection{Information Technology}

The term information technology is a two-fold term: Technology referring to technical skills (science), and "information " referring to the means, tools or ways in which knowledge and ideas are transferred from one person to another, or from one side to another, in order to interact and affect the knowledge or emotion of that person or body, to share experiences and ideas, or to convince or request for something (such as a meeting, scientific workshop, lecture, seminar, scientific conference, etc...) (Messaris, \& Humphreys 2006). IT is a set of tools and devices that provide information storage, processing and retrieval, as well as subsequent delivery to and from anywhere in the world (Turban, 2008).

\subsubsection{The Importance of Information Technology}

The use of technology in obtaining and transferring information has become one of the most important pillars which enables us to progress in all fields, in addition to saving time, effort, and money, whether it be in the field of obtaining, transferring or saving information. In fact, due to the development of the concept and uses of IT and the internet, the world has become like a small 'cosmic village' (Shin, 2001). Growing interest in the importance of information technology is due to several reasons, including:

- Increased influence of knowledge and information in modern societies.

- Increased influence and powers of staff and managers in modern departments.

- Increased development of communication networks and microprocessors (Porter, 2000).

\subsubsection{Requirements for the success of Information technology:}

Information technology is not just a technology, but also it is a philosophy and this requires human and legislative shift technology. The necessary requirements can be summarized under four key requirements, necessary to the success of applying Information technology. They are as follows: Hofmann\& Lehner (2001): 
1. Identify the organizations involved in the process of issuing building permits.

2. Identify the responsibilities and requirements of the organizations involved in issuing the building permits process.

3. Identify the processes, inputs, and outputs for these processes.

4. Design the proposed Information System for each organization individually and for all the organizations together.

\subsubsection{Information Technology Components:}

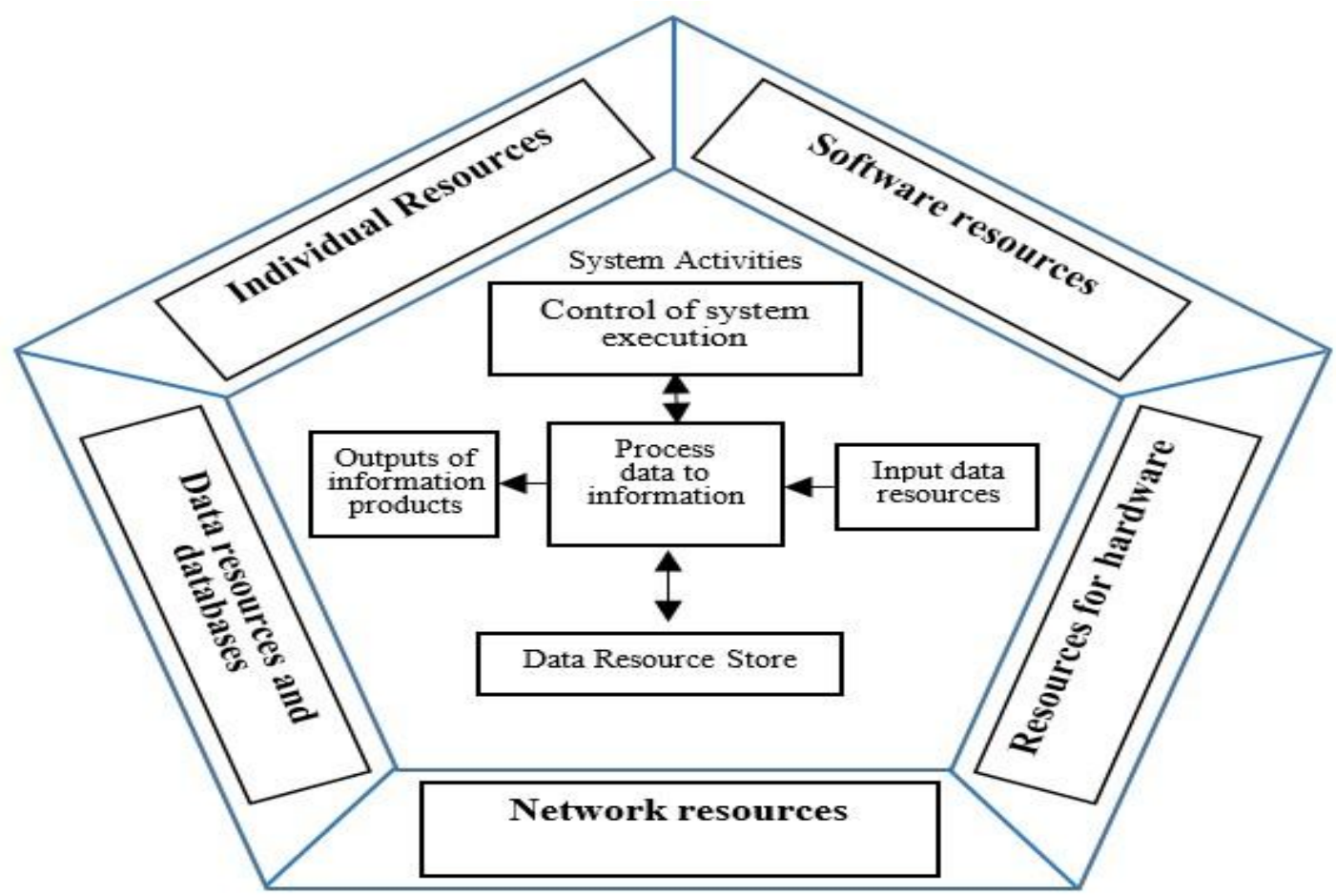

Figure 2 The information technology components. Source: O'Brien James A. and Marakas, George,

(2008),"Management Information Systems",9th ed., New York: McGraw-Hall /Irwin ,29

\section{Information technology consists of five components. They are as follows:}

1. Physical Components: Physical devices used in the activities of input, processing, and output which contain computer processing units, input devices, storage devices.

2. Software: These are registered programs, software owners, or software packages, i.e., they are software programs processed by computer manufacturers.

3. Human resources: They are qualified and trained cadres to carry out different activities. Therefore, the human element must be of different levels and competencies according to the nature of the system and its functions.

4. Databases: A group of data linked to each other or information stored on devices and data storage devices such as the hard disk drive of the computer and floppy disks or tapes.

5. Communication networks: is defined as the transmission of signals mediated by some means from the sender to the receiver and signal includes a message consists of data and information and the signal goes through a means of communication.

\section{Previous studies:}

Dewett (2007) The study aimed to identify the role of information technology in creating creativity, efficiency, and effectiveness for organizations and collected data through the study of the case and records of the research institutions. Several statistical methods were used, including correlation and regression coefficient. The study included several manufacturing establishments. The study concluded that creativity is an important factor in the success of organizations. Information technology plays an important role in creating creativity.

Saggi's (2002) study examined and summarized trade, foreign direct investment (FDI), and the transfer of international technology in order to identify where technology is transferred between investment companies in multiple geographical areas. It also highlighted the role of investment in promoting awareness of technological knowledge. 
The researcher used a descriptive approach in his study and focused on the importance of the technological aspects of international investment, and the role of technology in spreading multinational investment in different countries. In light of these findings, the study recommended further studies related to investment.

Maskus (1998) conducted a study regarding the role played by intellectual property rights in encouraging the guidance of foreign investment and transfer of technology. The research aimed to study the role of investment in general, and foreign investment in particular, and their effect on the production of technology and the increase of technological awareness through the transfer of mechanisms and tools, which contributes to technology investments. The researcher utilized a descriptive approach in his study, and he indicated the importance of foreign investment as a means of development, and as a means to enhance and develop economic skills. In light of these results, the researcher implored the necessity of making developmental efforts to attract foreign investments.

Schultz (1961) carried out a study which aimed to demonstrate the impact of knowledge, management, and employment on competitive advantages in investment, the emergence of new markets, and increased returns in finance and knowledge. The researcher used a descriptive approach to identify the nature of the relationship between knowledge (intellectual capital) and investment. He found that the importance of knowledge and its ability to increase investment maintains a positive correlation, as well as demonstrating a strong role in promoting technological innovation and providing innovative and sophisticated products.

Hawajreh and Sharabati (2012) investigated the impact of IT on the recruitment and management of knowledge. The study aimed to determine the impact of IT on knowledge management. The researchers used a descriptive analytical approach on a sample of 206 people working in a company using IT, and data was collected via questionnaires. The researchers found a positive relationship between IT, knowledge recruitment and management in their study. Maloney and Schumer (2010) conducted a study which examined the pivotal role of government investment, in order to realize the role government investments plays in technological knowledge research and development, as it generally increases the basic stock of knowledge. The researchers used a descriptive method, and their study concluded that the role played by investment in the production and development of knowledge technology is highly important.

The Al-Shourah\& Al-Shawabakeh study (2018) titled "the knowledge management processes and its role in improving organizational effectiveness: A field study Jordanian commercial banks " expects to inspect the effect of the movement of the key methodology of data the board on progressive execution. The researcher used the clarifying explanatory procedure and passed on a survey study for (144) official of the level of senior organization in the Jordanian business banks. The assessment found a couple of results, the hugest are: the nearness of the effect of Employment of Knowledge the board structures (age, scattering, and utilization) on legitimate execution.

The study of (Al-Rawajbeh\&Haboush, 2011) titled "Enhancing the Information Technology Functionality using Knowledge Management", intends to feature the principal objects of Information innovation applying in associations. At that point, the examination shows the job of Employment of Knowledge the executives in accomplishing the acknowledgment of Employment of Knowledge the executives and the significance of arriving at each procedure in the utilization of information technology The examination likewise exhibited the job of innovation in every one of the Information innovation and Employment of Knowledge the board and the degree of its commitment to the procedures of protection and capacity, transportation and support significantly extended the investigation to feature the job of Employment of Knowledge the executives and the requirement for the advancement of its legislature. The investigation concentrated on the examination of the upsides of utilizing the Employment of Knowledge the board using data innovation. The examination came to presume that Employment of Knowledge the executives considered as a piece of the Information innovation and the primary sponsor of its various applications as a facilitator and supporter to share, move and spare data.

The search pointed to the processes of employment of knowledge management in information technology are similar to those found in the companies to a certain extent, but different in essence aims and purposes. The aim is to provide a service to the community and to enhance the ability of competitiveness and profitability of the companies. Based on the necessity of software and hardware for the government environment, a conceptual model has been prepared for Knowledge management, which consists of sub-systems for each of the collection, organization, and application of knowledge. There are interconnected relationships between the three sub-systems, which support each other.

\section{The most important findings of the study:}

The current research investigates the impact importance of information technology in the employment of knowledge management. Therefore, the present research attempts to explain and clarify the nature of knowledge and its role in modern technology in all its forms and tools. 
- The main pedestal of employment knowledge in the management of higher education in Jordanian universities is strategy and commitment, information systems, culture, and communication.

- The study treated that the strategy and commitment serve as a force for knowledge management, information systems are working to improve and facilitate the exchange of employment of knowledge smoothly, culture as an important and a significant factor within the organization and finally believing that communication tools are physical such as the Internet and extranet.

\section{Methodology of the study: (methods and procedures)}

\subsection{Type and nature of the study:}

This investigation is fundamental as far as Basic and applied in the Ministry of education in Jordan, where the reason for Explanatory, Deductive in its inclination since it relies upon the board speculations and past examinations.

\subsection{Methods of data collection:}

The researcher depended on this study on the use of the descriptive-analytical method and style of the field study. The sources of information consist of two sources:

1. The secondary sources: The literature in management through the use of scientific references, researches and studies published in specialized magazines and journals, as well as articles and papers published.

2. The primary sources: The data that have been collected through the questionnaire that was designed and distributed to a study sample of the ministry of educations in Jordan, then data analyzed and processed.

\subsection{The study's population and sample:}

The study population was from the ministry of education in Jordan. The number of members of the population is (650) in the center of the ministry distributed in (23) directorates. The sample of the study was a random sample consisting of (80) employees in (8) directorates within the ministry center. The rate of questionnaires recovery has reached (72 questionnaires).

\subsection{Instrument of the study:}

The researcher designed and developed a questionnaire specifically for this purpose, based on hypotheses in addition to the dependent and independent variables, and then were presented to a group of expertise and competence people, who are faculty members in the College of Business and Finance at The University of Jordan and in Colleges of Administrative Sciences in other universities. Then some adjustments were made and re-formulated according to the observations and recommendations regarding ensuring the stability of the tool (questionnaire), through the use of tests (Cronbach Alpha).

\subsection{Reliability Test:}

(Cronbach alpha) test was used to measure the reliability of the measurement tool. The value of the questionnaire as a whole was $=0.965$ which is an excellent rate being higher than the acceptable rate which is $60 \%$. Also the $\propto$ value for each variable as follows:

Table 1 Reliability Test "Cronbach alpha"

\begin{tabular}{lll}
\hline$\propto$ value & Variable & \\
\hline 0.912 & Software, communication, database & \\
0.881 & human resources \\
0.761 & Physical components \\
0.923 & $\begin{array}{l}\text { The dependent variable of employment of knowledge } \\
\text { management }\end{array}$ \\
\hline
\end{tabular}

\subsection{Methods of data analysis:}

Analysis of the data was collected and processed by the Statistical Program Package for Social Sciences (SPSS), to gain access to the Pearson correlation coefficient. It also adopted a process of analysis on measures of descriptive statistics (percentages, statistical frequencies, the arithmetic average, and standard deviation) to indicate the characteristics of the sample. The study used measures of inferential statistics to reach the appropriate correlation coefficient, to analyze the study data and to test various hypotheses.

\section{The results of the study:}

The average and the standard deviation were extracted in order to describe the sample answers about the below paragraphs: 
1.Software (communication, database):

Table 2 Software, communication, database dimension.

\begin{tabular}{lll}
\hline Arithmetic average & Standard deviation & \\
\hline 3.9167 & .74588 & $\mathrm{a} 1$ \\
3.9167 & .89992 & $\mathrm{a} 2$ \\
3.9167 & .88413 & $\mathrm{a} 3$ \\
4.3056 & .68462 & $\mathrm{a} 4$ \\
4.3056 & .74378 & $\mathrm{a} 5$ \\
3.6944 & .89818 & $\mathrm{a} 6$ \\
3.7361 & .85569 & $\mathrm{a} 7$ \\
3.7639 & .89589 & $\mathrm{a} 8$ \\
3.8472 & .83345 & $\mathrm{a} 9$ \\
3.4306 & 1.00459 & $\mathrm{a} 10$ \\
3.4444 & 1.00546 & $\mathrm{a} 11$ \\
3.5556 & .94778 & $\mathrm{a} 12$ \\
3.5833 & .91544 & $\mathrm{a} 13$ \\
3.5972 & .88269 & $\mathrm{a} 14$ \\
3.6111 & .77923 & $\mathrm{a} 15$ \\
3.6944 & .83310 & $\mathrm{a} 16$ \\
\hline 3.7700 & .60485 & Total Average \\
\hline
\end{tabular}

It is clear that the trends are positive towards the above paragraphs and that because the arithmetic Averages are greater than the average measurement tool (3) also; it was found that the overall average of 3.77 reflects the approval of the sample towards the variable above.

\section{Human resources:}

Table 3 human resource dimension

\begin{tabular}{lll}
\hline Arithmetic average & Standard deviation & \\
\hline 3.5972 & .86659 & A17 \\
3.6250 & .84649 & A18 \\
3.6667 & .82223 & A19 \\
3.1944 & 1.02968 & A20 \\
3.2778 & 1.03763 & A21 \\
3.4028 & .91405 & A22 \\
\hline 3.4606 & .67974 & General average \\
\hline
\end{tabular}

It is clear that the trends are positive towards the above paragraphs and that because the arithmetic averages are greater than the average measurement tool (3) also it was found that the overall average of 3.4606 reflects the approval of the sample towards the variable above.

\section{Physical components:}

Table 4 Physical components dimension

\begin{tabular}{lll}
\hline Arithmetic average & Standard deviation & \\
\hline 3.8472 & .64261 & $\mathrm{a} 23$ \\
3.4583 & .88711 & $\mathrm{a} 24$ \\
3.2639 & .90372 & $\mathrm{a} 25$ \\
3.3750 & .94104 & $\mathrm{a} 26$ \\
2.8333 & .94943 & $\mathrm{a} 27$ \\
\hline 3.3556 & .64413 & General average \\
\hline
\end{tabular}

It is clear that the trends are negative towards paragraph (27) and that because the arithmetic averages are less than the average measurement tool (3) also it was found that the overall average is less than the average measurement tool (3). Also it was found that the overall average of 3.3556 reflects the approval of the sample towards the variable above.

\section{Employment of Knowledge management processes}


Table 5 Employment of Knowledge management processes dimensions

\begin{tabular}{lll}
\hline Arithmetic average & Standard deviation & \\
\hline 3.2361 & .81350 & $\mathrm{~b} 1$ \\
3.3889 & .79710 & $\mathrm{~b} 2$ \\
3.4028 & .78111 & $\mathrm{~b} 3$ \\
3.5833 & .76453 & $\mathrm{~b} 4$ \\
3.5833 & .78274 & $\mathrm{~b} 5$ \\
3.5972 & .81638 & $\mathrm{~b} 6$ \\
3.6250 & .79501 & $\mathrm{~b} 7$ \\
3.6528 & .82496 & $\mathrm{~b} 8$ \\
3.6806 & .78411 & $\mathrm{~b} 9$ \\
3.5139 & .83906 & $\mathrm{~b} 10$ \\
3.5139 & .85569 & $\mathrm{~b} 11$ \\
3.5417 & .88711 & $\mathrm{~b} 12$ \\
3.6944 & .83310 & $\mathrm{~b} 13$ \\
3.2917 & .94104 & $\mathrm{~b} 14$ \\
3.3750 & .94104 & $\mathrm{~b} 15$ \\
3.4306 & .93185 & $\mathrm{~b} 16$ \\
3.5139 & .88800 & $\mathrm{~b} 17$ \\
3.5556 & .94778 & $\mathrm{~b} 18$ \\
3.5556 & .94778 & $\mathrm{~b} 19$ \\
\hline 3.5124 & .66015 & General Total \\
\hline
\end{tabular}

It is clear that the trends are positive towards the above paragraphs and that because the arithmetic averages are greater than the average measurement tool (3) also it was found that the overall average of 3.5124 reflects the approval of the sample towards the variable above.

The Main hypothesis: There is no statistically significant impact at the level of $(\mathrm{P} \leq 0.05)$ for the information technology on the four processes of Employment of Knowledge management (acquisition and creation of knowledge, save and store knowledge, share and transfer of knowledge and apply and use of knowledge) in Ministry of education in Jordan.

\section{Hypothesis test results:}

Table 6 Result of the main- hypothesis

\begin{tabular}{llllll}
\hline $\mathrm{R} 2$ & $\mathrm{R}$ & Result of the main hypothesis & f SIG & f tabulated & f calculated \\
\hline 0.556 & 0.725 & Refuse & 0.000 & 2.81 & 26.208 \\
\hline
\end{tabular}

Multiple regression test was used, and from computer results in the previous table we found that the value of (f calculated $=26.208$ ) is greater than the tabular value, and since the decision rule is to accept the hypothesis of nihilism (Ho) if the calculated value is less than the tabular value and rejects the hypothesis of nihilism (Ho) if the calculated value greater than the tabular value, and therefore we reject the hypothesis nihilism (Ho), and accept the alternative hypothesis (Ha). This means that the independent variables combined are affecting the employment of knowledge management, and the relation is a strong relationship as $\mathrm{R}=0.725$ and the independent variables explain $55.6 \%$ of Employment of Knowledge management changes.

The first sub-hypothesis: there is no statistically significant effect at the level of $\mathrm{P}<0.05$ Software (communication, database) on the processes of Employment of Knowledge management in the Ministry of education in Jordan.

\section{Hypothesis test results:}

Table 7 Result of the first sub-hypothesis

\begin{tabular}{llllll}
\hline $\mathrm{R} 2$ & $\mathrm{R}$ & Result of the first sub-hypothesis & $\mathrm{t}$ SIG & $\mathrm{t}$ tabulated & $\mathrm{t}$ calculated \\
\hline 0.381 & 0.599 & Refuse & 0.000 & 1.9138 & 6.291 \\
\hline
\end{tabular}

Simple regression test was used, and from computer results in the previous table we found that the value of $(\mathrm{t}$ calculated $=6.291$ ) is greater than the tabular value, and since the decision rule is to accept the hypothesis of nihilism (Ho) if the calculated value is less than the tabular value and rejects the hypothesis of nihilism (Ho) if the calculated value greater than the tabular value, and therefore we reject the hypothesis nihilism (Ho), and accept the alternative hypothesis (Ha). 
This means that Software (communication, database) affecting the knowledge management, and the relation is a moderate relationship as $(\mathrm{R}=0.599)$ and the independent variable explains Percentage 38.1of Employment of Knowledge management changes.

\section{The second sub-hypothesis:}

there is no statistically significant effect at the level of $\mathrm{P}<0.05$ to human resource on the processes of Employment of Knowledge management in the Ministry of education in Jordan.

\section{Hypothesis test results:}

Table 8 Result of the second sub-hypothesis

\begin{tabular}{llllll}
\hline $\mathrm{R} 2$ & $\mathrm{R}$ & Result of the first sub-hypothesis & $\mathrm{t}$ SIG & $\mathrm{t}$ tabulated & $\mathrm{t}$ calculated \\
\hline 0.356 & 0.549 & Refuse & 0.000 & 1.9939 & 5.757 \\
\hline
\end{tabular}

Simple regression test was used, and from computer results in the previous table we found that the value of (t calculated $=5.757$ ) is greater than the tabular value, and since the decision rule is to accept the hypothesis of nihilism (Ho) if the calculated value is less than the tabular value and rejects the hypothesis of nihilism (Ho) if the calculated value greater than the tabular value, and therefore we reject the hypothesis nihilism (Ho), and accept the alternative hypothesis (Ha). This means that human resource the Employment of Knowledge management and the relation is a moderate relationship as $(\mathrm{R}=0.549)$ and the independent variable explains \%35.6 of Employment of Knowledge management changes.

The third sub-hypothesis: there is no statistically significant impact at the level of $\mathrm{P}<0.05$ for Physical components on the processes of Employment of Knowledge management in the Ministry of education in Jordan.

\section{Hypothesis test results:}

Table 9 Result of the third sub-hypothesis

\begin{tabular}{llllll}
\hline $\mathrm{R} 2$ & $\mathrm{R}$ & Result of the first sub-hypothesis & $\mathrm{t}$ SIG & $\mathrm{t}$ tabulated & $\mathrm{t}$ calculated \\
\hline 0.371 & 0.657 & Refuse & 0.000 & 1.9839 & 6.861 \\
\hline
\end{tabular}

Simple regression test was used, and from computer results in the previous table we found that the value of $(\mathrm{t}$ calculated $=6.861$ ) is greater than the tabular value, and since the decision rule is to accept the hypothesis of nihilism (Ho) if the calculated value is less than the tabular value and rejects the hypothesis of nihilism (Ho) if the calculated value greater than the tabular value, and therefore we reject the hypothesis nihilism (Ho), and accept the alternative hypothesis (Ha). This means that Physical components the Employment of Knowledge management and the relation is a moderate relationship as $\mathrm{R}=0.657$ and the independent variable explains \%37.1 of Employment of Knowledge management changes.

\section{Conclusions and recommendations}

The researcher draws clear conclusions from the great importance of information technology, which appears in each of the variables of research. Knowledge sets the foundation for everything new and useful in this world. The most prominent and most important products of knowledge are the modern technological techniques, which contributed greatly to the Employment of Knowledge Management Processes. The use of information technology in the ministry of educations in Jordan focuses on the use of information and communication technology to improve the implementation of government activities, improve government processes, reduce costs, improve performance, the strategic linkage between the minis tries and departments, and create a higher degree of empowerment. The role of Employment of Knowledge management in Information technology: The Information technology program considered as a practical embodiment of the Employment of Knowledge management as information organization can be used in solving a specific problem, or it is understandable analyzed and applied information in a regular way. Information technology means the use of information technology in dealing with the available knowledge at the governmental institutions, and in the work completion and performance monitoring, as it depends on the use of elements of information, knowledge, and communications in the planning and implementation of government policies towards achieving the overall objectives. In the light of the study's findings, the researchers recommended a set of recommendations as:

- The need to develop a specialized unit for Employment of Knowledge management in the ministry of education in Jordan, to effectively and efficiently continuity of work.

- Ministry employees' involvement in courses specialized in the function of Information technology and Employment of Knowledge management to increase their performance.

- Emphasize the need to provide enough administrative and financial support to activate the processes of Employment of Knowledge management at the ministry of education in Jordan. 
- The need to teach, modify and develop Employment of Knowledge Management Processes.

- Development of a framework to utilize information technology gained in the development and construction of modern Employment of Knowledge Management Processes.

- Activation and issuance of economic provisions regulating the knowledge and technological.

- Improved use of information technology and employment of knowledge management processes.

\section{References}

Al Rawajbeh, M., \&Haboush, A. (2011). Enhancing the eGovernment functionality using Knowledge Management. In World academy of Science, Engineering and Technology.

Al-Shourah, A. A., Irtaimeh, H. J. A., \& Al-Shawabakeh, K. M. (2018). The knowledge management processes and its role in improving organizational effectiveness: A field study Jordanian commercial banks. IJAME.

Bontis, N. (2001). Managing organizational knowledge by diagnosing intellectual capital: framing and advancing the state of the field. In Knowledge management and business model innovation (pp. 267-297). IGI Global.

Buckland, M. K. (1991). Information as thing. Journal of the American Society for information science, 42(5), 351360. Davenport, T. H., \&Prusak, L. (1998). Working knowledge: How organizations manage what they know. Harvard Business Press.

Chen, C. J., \& Huang, J. W. (2009). Strategic human resource practices and innovation performance-The mediating role of knowledge management capacity. Journal of business research, 62(1), 104-114.

Denning, S. (2006). Ten steps to get more business value from knowledge management. Strategy \& Leadership, 34(6), 11-16.

Dewett, Todd, (2007),Understanding the Relationship Between Information Technology and Creativity in Organizations, Creativity Research Journal www. Leaonline .com / doi/ abs.

Hawajreh, K. M., \& Sharabati, A. (2012). The impact of information technology on knowledge management practices. International Journal of Business, Humanities and Technology, 2(7), 32-46.

Hofmann, H. F., \& Lehner, F. (2001). Requirements engineering as a success factor in software projects. IEEE software, (4), 58-66.

Leonard, D., \& Sensiper, S. (1998). The role of tacit knowledge in group innovation. California management review, 40(3), 112-132.

Inkpen, A. C., \& Dinur, A. (1998). Knowledge management processes and international joint ventures. Organization science, 9(4), 454-468.

Maloney, C. B., \& Schumer, C. E. (2010, May). The pivotal role of government investment in basic research. In Final RD Report, United States Congress Joint Economic Committee. Retrieved on (pp. 19-04).

Maskus, K. E. (1998). The role of intellectual property rights in encouraging foreign direct investment and technology transfer. Duke J. Comp. \& Int'l L., 9, 109.

Messaris, P., \& Humphreys, L. (Eds.). (2006). Digital media: Transformations in human communication. Peter Lang.

Nonaka, I., \& Konno, N. (1998). The concept of "Ba": Building a foundation for knowledge creation. California management review, 40(3), 40-54.

O'Brien, J. A., \& Marakas, G. M. (2006). Management information systems (Vol. 6). McGraw-Hill Irwin.

Portes, A. (1997). Immigration theory for a new century: Some problems and opportunities. International migration review, 31(4), 799-825.

Porter, M. E. (2000). Location, competition, and economic development: Local clusters in a global economy. Economic development quarterly, 14(1), 15-34.

Robinson, H. S., Anumba, C. J., Carrillo, P. M., \& Al-Ghassani, A. M. (2006). STEPS: a knowledge management maturity roadmap for corporate sustainability. Business Process Management Journal, 12(6), 793-808.

Saggi, K. (2002). Trade, foreign direct investment, and international technology transfer: A survey. The World Bank Research Observer, 17(2), 191-235.

Schank, R. C., \& Abelson, R. P. (2013). Scripts, plans, goals, and understanding: An inquiry into human knowledge structures. Psychology Press.

Schultz, T. W. (1961). Investment in human capital. The American economic review, 1-17.

Shin, N. (2001). The impact of information technology on financial performance: the importance of strategic choice. European Journal of Information Systems, 10(4), 227-236.

Turban, E. (2008). Information technology for management. John Wiley \& Sons, Inc.

Vosko, L. F. (Ed.). (2006). Precarious employment: Understanding labour market insecurity in Canada (pp. 43-66). Montreal: McGill-Queen's University Press. 
Pike, S., Roos, G., \& Marr, B. (2005). Strategic management of intangible assets and value drivers in R\&D organizations. R\&D Management, 35(2), 111-124.

Porter, M. E. (2000). Location, competition, and economic development: Local clusters in a global economy. Economic development quarterly, 14(1), 15-34.

Wilson, T. D. (2002). The nonsense of knowledge management. Information research, 8(1), 8-1. Zagzebski, L. (2017). What is knowledge?. The Blackwell guide to epistemology, 92-116. 